\title{
USEFULNESS OF SIMPLE SHIELDING TECHNIQUE USING MULTILEAF COLLIMATOR IN BREAST RADIATION THERAPY
}

\author{
KYU CHAN LEE ${ }^{*}$, SEOK HO LEE*, SEUNG HEON LEE", KIHOON SUNG ${ }^{*}$, SO HYUN AHN", JINHO CHOI", \\ KAP SANG DONG*, HYO JIN KIM", YONG SEON CHUN ${ }^{\dagger}$, and HEUNG KYU PARK ${ }^{\dagger}$ \\ *Department of Radiation Oncology, Gil Medical Center, School of Medicine, Gachon University \\ ${ }^{+}$Department of Surgery, Gil Medical Center, School of Medicine, Gachon University,
}

Received September 25, 2014 / 1st Revised November 3, 2014 / 2nd Revised November 16, 2014 /

Accepted for Publication November 20, 2014

\begin{abstract}
This study was designed to assess whether the conventional tangential technique, using a multileaf collimator (MLC), allows a reduced dose to the organs at risk (OAR) in breast radiation therapy. A total of forty right and left 20 for each breast cancer patients that underwent radiation therapy after breast conserving surgery were included in this study. For each patient, the planning target volume (PTV) and OAR (heart, left anterior descending artery (LAD), liver and lung) were defined and dose distribution were produced for conventional tangential beams using 6 MV photons. The treatment plans were made using the following two techniques for all patients. For the first plan (P1), MLC was designed to shield as much of OAR as possible without compromising the coverage of PTV. In the second plan (P2), the treatment plan was created without using MLC. Dose-volume histograms for OARs were calculated for all plans. For left breast cancer, the percentage of maximum dose $\left(D_{\max \%}\right)$ and mean dose $\left(\mathrm{D}_{\text {mean } \%}\right)$ of OARs (heart and LAD) were calculated, and for right breast cancer, the percentage of the mean dose $\left(D_{\text {mean } \%}\right)$ of the liver was calculated. The $D_{\text {mean } \%}$ of the lung was calculated in all patients.

The mean values of $\mathrm{D}_{\max \%}$ of the heart $(86.9 \pm 19.5 \%$ range, $35.1-100.6 \%)$ in P1 were significantly lower than in P2 (98.3 $\pm 3.4 \%$ range, $91.7-105.2 \%)(\mathrm{p}=0.001)$. The mean values of $\mathrm{D}_{\max \%}$ of $\mathrm{LAD}(78.4 \pm 22.5 \%$ range, $26.5-99.7 \%)$ in P1 was significantly lower than in P2 $(93.3 \pm 8.1 \%$ range, $67.9-102.1 \%)(\mathrm{p}<0.001)$. In P1, the mean values of $\mathrm{D}_{\text {mean\% }}$ of the liver $(4.8 \pm 2.0 \%)$ were significantly lower than in P2 $(6.2 \pm 2.5 \%)(\mathrm{p}<0.001)$. The mean values of $\mathrm{D}_{\text {mean\% }}$ of the lung were significantly lower in P1 $(9.3 \pm 2.3 \%)$ than in P2 $(9.7 \pm 2.4 \%)(\mathrm{p}<0.001)$. P1, by using MLC, allows a significantly reduced dose to OAR compared with P2. We can suggest that it is reasonable to routinely use MLC in the conventional tangential technique for breast radiation therapy considering the primary tumor location.
\end{abstract}

Keywords : Breast cancer, Multileaf collimator, Organs at risk

\section{INTRODUCTION}

Adjuvant radiation therapy (RT) in breast cancer patients receiving breast conservation surgery (BCS) is the standard treatment approach. It is well known that that adjuvant RT significantly reduce the relative risk of locaoregional recurrence and the breast cancer

Corresponding author : Seok Ho Lee, souko@gilhospital.com

1198 Guwol-dong, Namdong-gu, Incheon 405-760, Korea mortality rate [1]. Furthermore, this treatment approach which is effective methods to decrease locoregional relapse with good cosmetic results [2].

The initial RT techniques for these patients is to treat the whole breast using a two-field tangential technique (2F-TT). However, there is a possible risk of unwanted radiation dose to the organs at risks (OARs) such as the heart, lung, and liver. There is also evidence that the nonbreast cancermortality from 
heart disease and lung cancer after 10-15 years of RT increase although the adjunvant RT can decrease locoregional recurrence and breast cancer mortality $[3,4]$. It is well known that the RT dose and pre-existing ischemic heart disease can increase the risk of radiation induced cardiac morbidity. Even the patient with preexisting cardiac risk factors such as hypertension, diabetes, and obesity can increase the risk from RT than other patient [5]. Ithas been reported that the left breast cancer patients treated with RT receive doses of 1 to 5 Gy to the heart and the exposure at this level can cause ischemic heart disease, although the risk magnitude after RT to the heart is uncertain [6-9].

Therefore, a radiation dose to OARs, such as critical structures of the heart and left anterior descending artery (LAD) within the RT field, should be minimized as possible.

Among the techniques reducing the dose to OARs, the shielding techniques that uses multileaf collimator (MLC) has been the standard RT technique in most of cancer patients who needed RT. Actually, OARs shielding technique using MLC is clinicallyconducted in many institutions in breast cancer patients treated with 2F-TT. However, the comparative analysis of the effects of RT on both OARs and PTV between RT plans with and without MLC has not been performed yet, although there are a few reports concerning the effects of RT on OARs after MLC shielding in breast cancerpatients. $[10,11]$. This study was designed to assess whether 2F-TT using MLC minimizes the dose to OAR and impairs the coverage of target volume in breast RT.

\section{MATERIALS AND METHODS}

A total of forty right and left, 20 for each, breast cancer patients that underwent radiation therapy after breast conserving surgery were included in this study.

\subsection{Image Acquisition for RT planning and Treatment}

All patients were scanned in supine position on a breast board, with the arms extended above the head. For RT planning, non-contrast enhanced computed tomography (CT) scans were performed in free-breathing with $0.5 \mathrm{~cm}$ slice intervals, from $\mathrm{C} 1$ to below the diaphragm encompassing the entire liver. Radiopaque wires were placed to locate the scars on $\mathrm{CT}$ images. CT images were transferred to a RT planning software, Eclipse version 10.0 (Varian, Plato Alto, USA).

\subsection{Delineation of Target and Organ at risk}

The same physician performed the target and OAR delineation procedures for consistency. For each patient, the planning target volume (PTV) and OAR (heart, LAD, liver and lung) were contoured on each CT images. The planning target volume (PTV) was defined as the palpable breast encompassing clinical target volume (CTV), which was defined as the primary tumor bed, including surgical clips and seroma plus a margin of $5 \mathrm{~mm}$. The boundaries for PTV contouring were as follows; sternoclavicular junction superiorly, inframammary sulcus inferiorly, sternal-rib junction medically, axillary vessle laterally, $5 \mathrm{~mm}$ below the skin ventrally, and pectoralis major muscle dorsally. The heart was contoured as follows; atria and auricles from the level of the aorta root and pulmonary trunk to the heart apex. The left ventricles and LAD were delineated. LAD was contoured from the aorta root to the apex of the heart with a $5 \mathrm{~mm}$ diameter to take into account of any uncertainties relating to respiration and cardiac movement. Although LAD could be visualized in most patients, the position of LAD in case not possible to confirm was identified in accordance to its location overlying the interventricular septum [12]. Additionally, OARs, particularly the lung and liver, were delineated.

\subsection{Treatment Planning and Analysis}

For each patient, the treatment planning was performed with two tangential beams using $6 \mathrm{MV}$ photons. Two opposing $6 \mathrm{MV}$ tangential conformal fields with multileafcollimators were used for 2F-TT. The 2F-TT field were as follows; inferior border of the clavicle superiorly, $1 \mathrm{~cm}$ below the inframammary fold inferiorly, midline medially, and anterior border of serratus anterior laterally. Depth of the lung tissue included in the 2F-TT fields was constrained to $3 \mathrm{~cm}$, which was followed by the recommendation in the guidelines published by the European oraganization for research and treatment of cancer (EORTC) and the European Society of Mastology (EUSOMA) [13]. The treatment plans included 2F-TT with and without shielding using MLC. The treatment plans were made using the following two techniques for all patients. For the first plan (P1), the MLC was designed to shield as much of OAR as possible without compromising the coverage of PTV. In the second plan (P2), the treatment plan wascreated without using MLC. Initially, the treatment plan using 2F-TT without using MLC was planned for simulation purposes. MLC shielding was generated based on wiring during a simulation procedure shown in Fig. 1. 

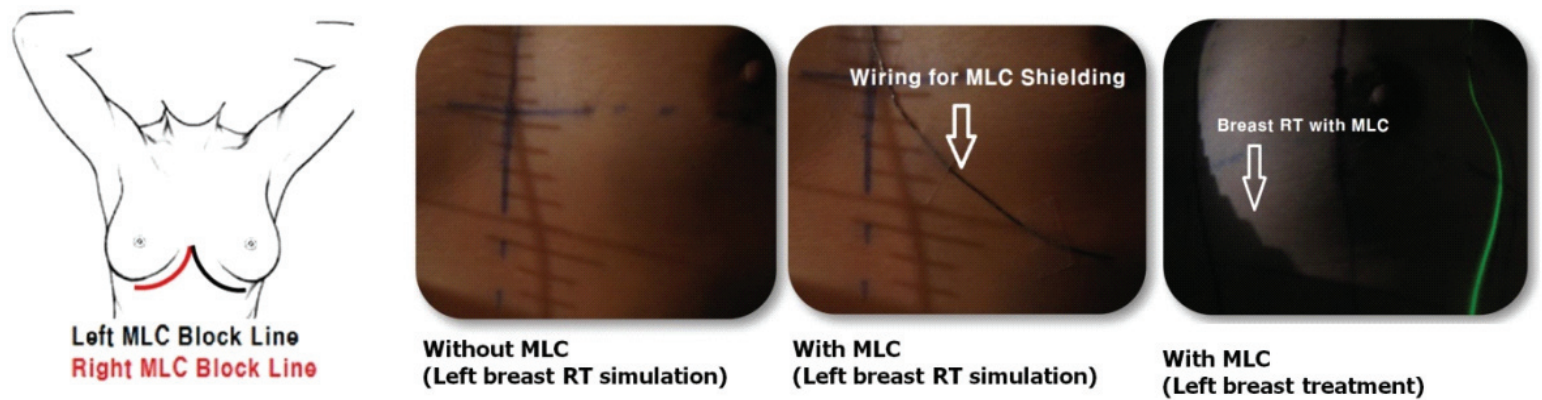

Fig. 1. The MLC shielding technique in left breast radiation therapy with a conventional breast tangential field design

Table 1. Dosimetric Comparison for the Heart and Left Anterior Descending Artery in 20 Left Breast Cancer Patients.

\begin{tabular}{|c|c|c|c|c|c|c|c|c|}
\hline \multirow{4}{*}{$\begin{array}{c}\text { mean } \pm \text { Std } \\
\text { Dose }(\%)\end{array}$} & \multicolumn{4}{|c|}{ Heart } & \multicolumn{4}{|c|}{ LAD* } \\
\hline & P1 & $\mathbf{P 2}$ & P1 & $\mathbf{P 2}$ & P1 & $\mathbf{P 2}$ & P1 & $\mathbf{P 2}$ \\
\hline & \multicolumn{2}{|c|}{$\mathbf{D}_{\max }^{\dagger}$} & \multicolumn{2}{|c|}{$\mathbf{D}_{\text {mean }}{ }^{\ddagger}$} & \multicolumn{2}{|c|}{$\mathbf{D}_{\max }$} & \multicolumn{2}{|c|}{$\mathbf{D}_{\text {mean }}$} \\
\hline & $86.9 \pm 19.5$ & $98.3 \pm 3.4$ & $6.4 \pm 2.3$ & $8.2 \pm 2.7$ & $78.4 \pm 22.5$ & $93.3 \pm 8.1$ & $34.0 \pm 18.9$ & $46.8 \pm 16.9$ \\
\hline Dose (Gy) & $42.6 \pm 9.0$ & $48.5 \pm 1.4$ & $3.1 \pm 1.1$ & $4.0 \pm 1.3$ & $39.5 \pm 11.3$ & $47.0 \pm 4.0$ & $17.1 \pm 9.5$ & $23.6 \pm 8.5$ \\
\hline p-value & \multicolumn{2}{|c|}{0.001} & \multicolumn{2}{|c|}{$<0.001$} & \multicolumn{2}{|c|}{$<0.001$} & \multicolumn{2}{|c|}{$<0.001$} \\
\hline
\end{tabular}

${ }^{*}$ Left anterior descending artery

${ }^{+}$The maximum dose

${ }^{\ddagger}$ The mean dose

Each physician approved the positioning of the wiring based on our policy without compromising the coverage of the target (PTV including palpable breast tissues). Each plan was optimized and evaluated based on ICRT 62 criteria [14]. A total prescription dose of 50.4 Gy in 28 fractions (1.8 Gy per fraction) to PTV was planned in $\mathrm{P} 1$ and $\mathrm{P} 2$. For OARs comparison, all plans ( $\mathrm{P} 1$ and $\mathrm{P} 2$ ) were normalized to the mean dose of PTV to 50.4 Gy. Dose-volume histograms (DVHs) for the OARs were calculated and evaluated for all plans. The generated plans were compared using DVHs for PTV and OAR for each patient.

A comparison of the dosimetric values for each plan was performed. For left breast cancer, the percentage of the maximum dose $\left(\mathrm{D}_{\max \%}\right)$ and mean dose $\left(\mathrm{D}_{\text {mean } \%}\right)$ of OARs (heart and LAD) were calculated, and for right breast cancer, the percentage of the mean dose $\left(D_{\text {mean } \%}\right)$ of the liver was calculated. The $\mathrm{D}_{\text {mean\% }}$ of the lung was calculated in all patients. For PTV comparison, the homogeneity index (HI) and conformity index (CI), which were defined by the Radiation Therapy Oncology Group, were analyzed. The HI and CI was calculated in accordance to the following equations,

Conformity index ${ }_{\text {RTOG }}=\mathbf{V}_{\mathrm{RI}} / \mathrm{TV}$

,where VRI: volume of the reference isodose, TV: target volume, and

Homogeneity index ${ }_{\text {RTOG }}=\mathbf{I}_{\text {max }} /$ RI

,where $\mathrm{I}_{\max }$ : maximum isodose in the target, RI: refer- ence isodose.

The results of P1 and P2 plans were compared with the two-sided Wilcoxon matched pair signed rank test which is a non-parametric statistical hypothesis test used when comparing two related samples, matched samples, or repeated measurements on a single sample to assess whether their population mean ranks differ. The threshold for statistical significance was $\leq 0.05$.

\section{RESULTS AND DISCUSSION}

\subsection{Normal Tissues (OARs)}

The mean values of $D_{\max \%}$ of the heart (86.9 $19.5 \%$; range, $35.1-100.6 \%$ ) in P1 were significantly lower than in $\mathrm{P} 2 \quad(98.3 \pm 3.4 \%$; range, 91.7-105.2\%) $(\mathrm{p}=0.001)$. The mean values of $\mathrm{D}_{\max \%}$ of LAD (78.4 \pm $22.5 \%$ range, $26.5-99.7 \%$ ) in $\mathrm{P} 1$ was significantly lower than in $\mathrm{P} 2(93.3 \pm 8.1 \%$ range, $67.9-102.1 \%)$ $(p<0.001)$. The all values of $D_{\max \%}$ of the heart and LAD in $\mathrm{P} 1$ were lower than in P2. Furthermore, due to a greater shielding effects in some patients, there was wider range of the $\mathrm{D}_{\max \%}$ distribution of the heart and LAD in $\mathrm{P} 1$ than in $\mathrm{P} 2$.

The mean values of $\mathrm{D}_{\text {mean } \%}$ of LAD $(34.0 \pm 18.9 \%)$ in P1 was significantly lower than in P2 (46.8 \pm $16.9 \%)(p<0.001)$. The results of a dosimetric comparison for the heart are shown in Table 1. The DVHs of the P1 technique shows a lower irradiated volume of the heart than the P2 technique. MLC shielding 


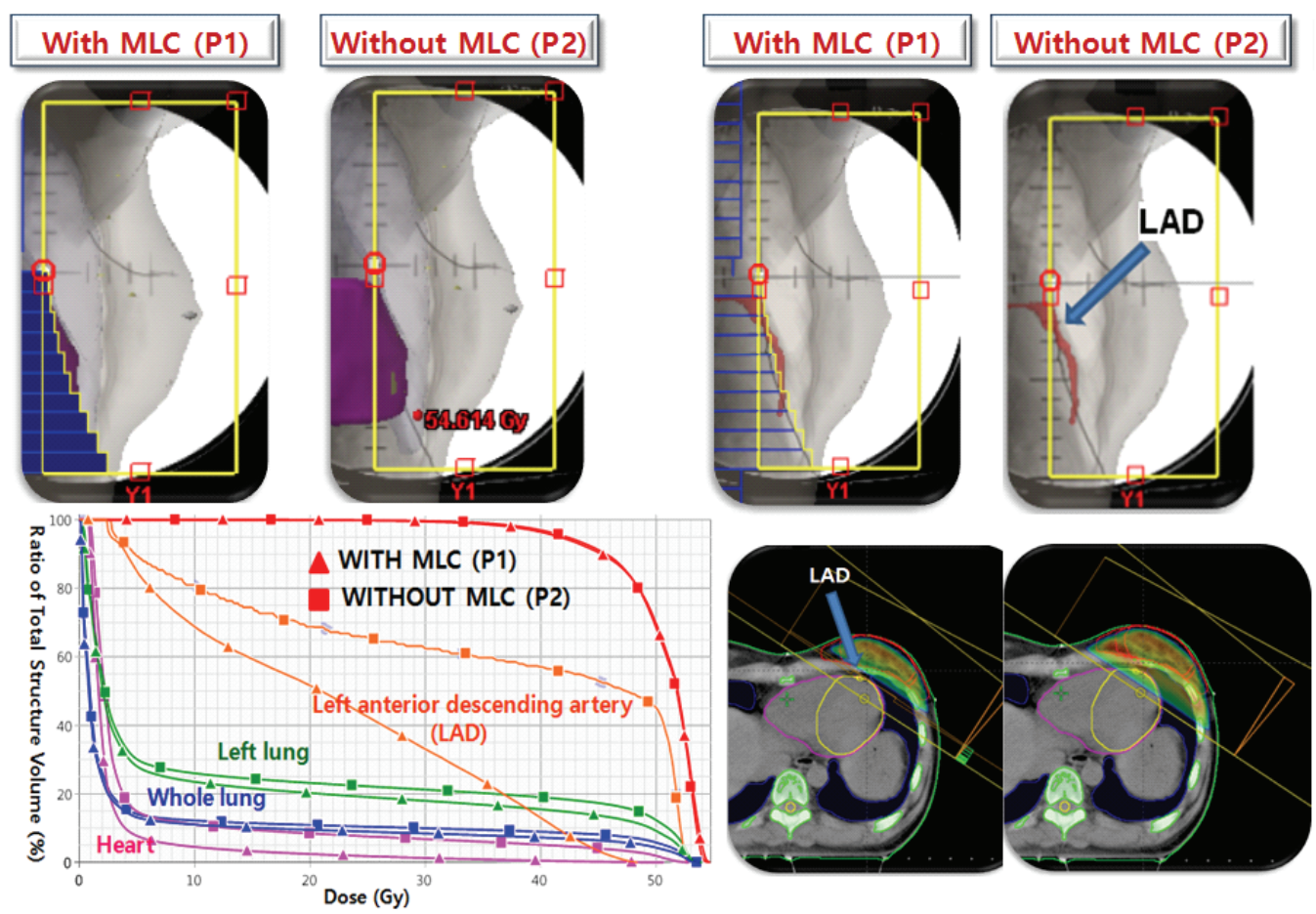

Fig. 2. Comparison of dose-volume histograms (DVHs) for P1 (triangle) vs. P2 (square) in the left breast. The DVHs of the P1 technique shows a lower irradiated volume of the left anterior descending coronary artery and heart than the P2 technique $(p<0.001)$. The mean values of $\mathrm{D}_{\text {mean } \%}$ of the whole and ipsilateral lungwere significantly lower in P1 than in P2. The V5 of the whole and ipsilateral lung was also significantly lower than in $\mathrm{P} 2$.

Table 2. Dosimetric Comparison for Liver in 20 Right Breast Cancer Patients.

\begin{tabular}{|c|c|c|c|}
\hline \multicolumn{4}{|c|}{ Liver } \\
\hline \multirow{2}{*}{$\begin{array}{c}\text { Volume (cc) } \\
\text { mean } \pm \text { Std }\end{array}$} & \multicolumn{2}{|c|}{$1137.0 \pm 211.4$} & \multirow[b]{2}{*}{ p-value } \\
\hline & P1 & $\mathbf{P 2}$ & \\
\hline $\mathrm{D}_{\text {mean }}^{*}(\%)$ & $4.8 \pm 2.0$ & $6.2 \pm 2.5$ & $<0.001$ \\
\hline $\mathrm{V} 20^{\dagger}(\%)$ & $3.5 \pm 1.2$ & $5.1 \pm 1.6$ & $<0.001$ \\
\hline $\mathrm{V} 30^{\neq}(\%)$ & $2.9 \pm 0.9$ & $4.3 \pm 1.4$ & $<0.001$ \\
\hline
\end{tabular}

"The mean dose

${ }^{\dagger}$ Proportion of the liver receiving $20 \mathrm{~Gy}$

${ }^{\ddagger}$ Proportion of the liver receiving $30 \mathrm{~Gy}$

Table 3. Dosimetric Comparison for Lung in All 40 Breast Cancer Patients.

\begin{tabular}{cccc}
\hline \multirow{2}{*}{ mean \pm Std } & \multicolumn{2}{c}{ Lung $^{*}$} \\
\cline { 2 - 4 } & P1 & P2 & p-value \\
\hline $\mathrm{D}_{\text {mean }}{ }^{\dagger}(\%)$ & $9.3 \pm 2.3$ & $9.7 \pm 2.4$ & $<0.001$ \\
$\mathrm{~V} 5^{\dagger}(\%)$ & $11.6 \pm 3.2$ & $12.0 \pm 3.2$ & $<0.001$ \\
\hline
\end{tabular}

*Whole lung

${ }^{\dagger}$ The mean dose

${ }^{\ddagger}$ Proportion of the lung receiving 5 Gy

Table 4. Dosimetric Comparison for Ipsilateral Lung in Right and Left, 20 for Each, Breast Cancer Patients.

\begin{tabular}{cccc|ccc}
\hline \multirow{2}{*}{ mean \pm Std } & \multicolumn{2}{c|}{ Right lung $(\mathbf{n}=\mathbf{2 0})^{*}$} & \multicolumn{3}{c}{ Left lung(n=20) $^{\dagger}$} \\
\cline { 2 - 8 } & $\mathbf{P 1}$ & $\mathbf{P 2}$ & p-value & P1 & P2 & p-value \\
\hline $\mathrm{D}_{\text {mean }}{ }^{*}(\%)$ & $17.8 \pm 2.2$ & $18.3 \pm 2.6$ & 0.001 & $16.1 \pm 3.2$ & $16.9 \pm 3.6$ & 0.001 \\
\hline $\mathrm{V}^{\S}(\%)$ & $24.2 \pm 3.0$ & $24.9 \pm 3.3$ & $<0.001$ & $21.1 \pm 3.7$ & $22.4 \pm 4.2$ & $<0.001$ \\
\hline
\end{tabular}

*Right breast cancer patients

${ }^{\dagger}$ Left breast cancer patients

${ }^{\ddagger}$ The mean dose

${ }^{\S}$ Proportion of the lung receiving 5 Gy 
effects for the heart in left breast cancer shows a lower irradiated volume of the heart (Fig. 2).

The mean values of $\mathrm{D}_{\text {mean } \%}$ of the liver $(4.8 \pm 2.0 \%)$ in P1 were significantly lower than in P2 $(6.2 \pm 2.5 \%)$ $(\mathrm{p}<0.001)$. The mean values of $\mathrm{D}_{\text {mean } \%}$ of lung $(9.3 \pm$ $2.3 \%)$ in $\mathrm{P} 1$ was significantly lower than in $\mathrm{P} 2(9.7 \pm$ $2.4 \%)(p<0.001)$. In dosimetric comparison for ipsilateral lung in right and left, 20 for each, breast cancer patients, the mean values of $\mathrm{D}_{\text {mean } \%}$ of in $\mathrm{P} 1$ were significantly lower than in $\mathrm{P} 2$. The results of a dosimetric comparison for the liver and lung are summarized in Table 2, 3, and 4. respectively.

A comparison of the dose-volume histograms in P1 and P2 and MLC shielding technique are shown in Fig. 3.

For the evaluation of the effects of RT for lung, we introduced the percentage of the mean dose $\left(D_{\text {mean } \%}\right)$ and the proportion of lung receiving 5 Gy (V5). There has been reports that the mean lung dose and V5 was the critical factors in limiting the toxicity for patients who received RT to the lung [15-17]. There has also been a report that showed that larger low-dose volume of V5 on the total lung might contribute to RT pneumonitis, especially for the lower-dose regions [18]. It is not exactly known how the levels of radiation exposure can lead to deteriorating effects on OARs. In US SEER cancer registries, there was a significant increase in the mortality from lung cancer observed
10-20 years after RT for early breast cancer [19].

Although the absolute RT dose to the liver was generally not reached to RT tolerance dose in right breast cancer patients who received adjuvant RT, in our study, the RT doses (mean dose, V20 and V30) to the liver showeda significant reduction in $\mathrm{P} 1$ than in P2. Because the occurrence of radiation induced liver disease (RILD) is associated with patient's disease status (liver cirrhosis, Child-Pugh grade, and the presence of hepatitis B), the effects of RT should be considered, especially in patients with poor hepatic reservoir [20,21]. We introduced the mean liver dose, $\mathrm{V} 20$ and V30, for an evaluation of the analysis in this study. This was determined based on the report that V20 and V30 were good parameters for RILD.

In contrary to the reports on the RT effects for the liver in right breast cancer, there are many reports concerning the RT effects for the heart. There is a report that the radiation exposure to the heart increases the risk of ischemic heart disease, proportionally to the mean dose to the heart [5]. It has been well established that patients who receive left breast RT have an increased cardiac morbidity and mortality [19,22]. In a previous report [11], they also assessed the effects of cardiac MLC shielding on target coverage. They reported that the mean and maximum LAD dose was $6.7 \pm 4.3$ Gy and 40.3 $\pm 10.1 \mathrm{~Gy}$, respectively.

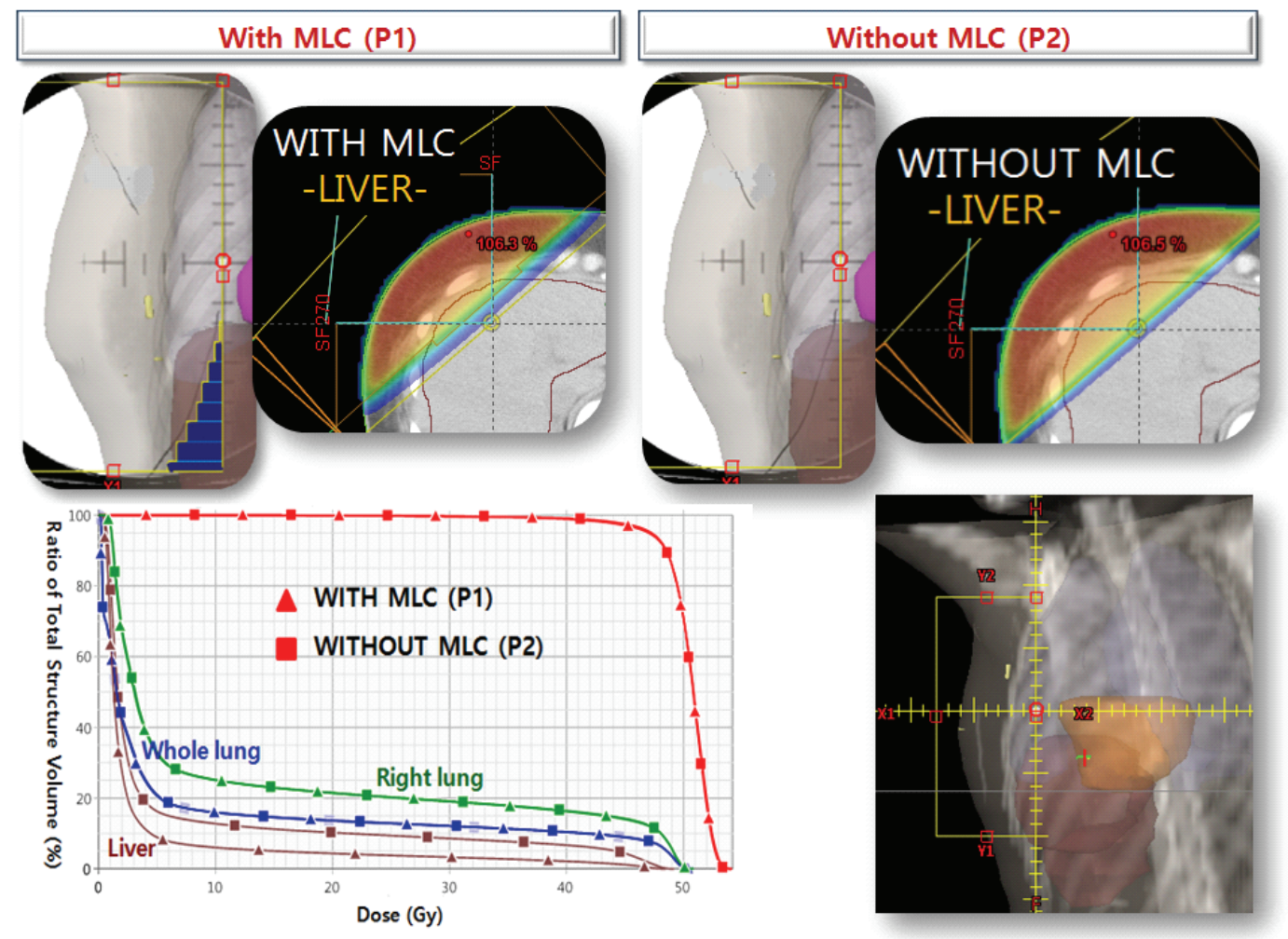

Fig. 3. Comparison of dose-volume histograms (DVHs) for $\mathrm{P} 1$ (triangle) vs. $\mathrm{P} 2$ (square) in the right breast. The DVHs of the P1 technique show a lower irradiated volume of the liver than the P2 technique $(p<0.001)$. In $\mathrm{P} 1$, the mean values of $\mathrm{D}_{\text {mean } \%}$ of the liver $(4.7 \pm 1.9 \%)$ were significantly lower than in P2 $(6.2 \pm 2.5 \%)(\mathrm{p}<0.001)$. 
Table 5. Dosimetric Comparison for PTV in All 40 Breast Cancer Patients.

\begin{tabular}{cccc}
\hline mean \pm Std & P1 & P2 & p-value \\
\hline PTV mean dose $(\mathrm{Gy})$ & 50.4 & 50.4 & 1 \\
PTV $\left(\mathrm{V}_{95 \%}\right)^{*}$ & $4.7 \pm 1.0$ & $5.13 \pm 1.2$ & 0.001 \\
PTV $\left(\mathrm{V}_{105 \%}\right)^{\dagger}$ & $10.5 \pm 7.4$ & $11.86 \pm 17.9$ & $<0.001$ \\
$\mathrm{CI}^{\dagger}$ & $1.09 \pm 0.01$ & $1.08 \pm 0.01$ & 0.056 \\
$\mathrm{HI}^{\S}$ & $1.46 \pm 0.2$ & $1.57 \pm 0.3$ & $<0.001$ \\
\hline
\end{tabular}

*The planning target volume receiving at least $95 \%$ of prescripbed dose

${ }^{\dagger}$ The planning target volume receiving at least $105 \%$ of prescripbed dose

${ }^{\ddagger}$ Conformity index, ${ }^{\S}$ Homogeneity index,

Whereas, the mean and maximum LAD dose in our study was $17.1 \pm 9.5$ and $39.5 \pm 11.3$, respectively. Although the maximum LAD doses were similar between the studies, the mean LAD doses were higher in our study. The reason for this discrepancy can be explained by the way in which MLC positioning for cardiac shielding is performed during a different time point between the studies. In the previous study [11], MLC shielding has been performed before simulation whereas in this study, MLC shielding was performed during simulation considering the coverage of breast parenchyme (PTV).

\subsection{Target Volumes (PTV)}

We initially planned with aim of normalized the same mean dose (50.4 Gy) of PTV to both P1 and $\mathrm{P} 2$. Therefore, the mean dose between P1 and P2 in both breasts was the same and shows no significant difference. The PTV V95\% and V105\% of P1 were significantly lower than that of $\mathrm{P} 2(\mathrm{p}=0.001)$. In $\mathrm{P} 1$, the CI was significantly lower than in $\mathrm{P} 2(\mathrm{p}=0.056)$. However, The HI was significantly lower in P2 $(\mathrm{p}<0.001)$ (Table 5).

The role of RT in breast cancer management is very important. However, RT is also associated with morbidity and mortality. Here, we analyzed the effects of RT on PTV and OARs using MLC shielding in 2F-TT and demonstrated a substantially reduced RT doses to OARs in P1 compared to P2. There is a recent report that cardiac shielding via MLC reduces RT dose to cardiac tissues at the expense of PTV coverage [12]. In this report, the mean RT dose to the heart and LAD were calculated and analyzed for 67 patients who underwent adjuvant RT to the left breast or chest wall. However, the RT doses to OAR and PTV between RT plans with and without MLC was not compared and only left breast cancer patients was enrolled in that study [12]. They concluded that there was a sacrifice of PTV coverage. Whereas we initially normalized the mean dose of PTV to both P1 and P2, and then compared and analyzed the RT doses to OARs and PTV (PTV 95\%, 105\%). Therefore, there was no difference in the PTV mean dose between P1 and P2, contrary to the previous report [12].

Our study shows that there was no significant difference in the PTV mean dose between P1 and P2. Although the result of CI was not significantly different, HI, PTV $\mathrm{V}_{95 \%}$ and $\mathrm{V}_{105 \%}$ was significantly lower in $\mathrm{P} 1$ than in $\mathrm{P} 2$, which appears to be the result from the effects of MLC shielding of PTV in the lower inner quadrant (LIQ) of the breast. There are many reports that most local recurrences in breast cancer patients develop in the near-field of the primary tumor $[23,24]$. Therefore, if the primary breast cancer is located in LIQ, the MLC shielding technique should be carefully performed on a case-by-case basis. Furthermore, careful MLC shielding should be performed based on variable factors. Age, tumor grade, negative estrogen receptor, and ductal carcinoma in situ presence has been well-known factors to increase the local recurrence, which should also be considered in deciding the use and extent of MLC shielding [25-27]. The disease history of patients, such as ischemic heart disease, and the use of cardiotoxic chemotherapy, such as Adriamycin, are also important factors to be considered [22]. The local recurrence risk and RT induced morbidities of OARs should be well balanced.

We could not draw any conclusion on which technique is better for reducing OARs RT doses without compromising PTV coverage. Although well-designed comparative studies between these techniques are needed, we believe that the use of MLC shielding technique is a very simple technique for effectively reducing OAR doses.

There are several limitations of our study. First, we did not evaluate the occurrence of morbidity relating to OAR irradiations. Nevertheless, it is possible that the results in this study may provide additional information to the MLC effects in breast RT. Another 
limitation is the retrospective nature of this study. Although, there is difficulty implementing this in reality, the prospective and comparative design will be needed to determine whether MLC shielding technique in breast RT is practically effective or not.

\section{CONCLUSION}

The results of this study indicates that the use of MLC for OAR shielding have a significant role in reducing RT dose to OARs. Based on the results of a dosimetric comparison between $\mathrm{P} 1$ and $\mathrm{P} 2$, we can suggest that it is reasonable to routinely use MLC in the conventional tangential technique for breast RT. However, a careful patient selection should be considered, especially in a case where the primary breast tumor is located in LIQ.

\section{REFERENCES}

1. Darby S, McGale P, Correa C, et al. Effect of radiotherapy after breast-conserving surgery on 10-year recurrence and 15-year breast cancer death: Meta-analysis of individual patient data for 10,801 women in 17 randomised trials. Lancet. 2011;378(9804):1707 - 1716.

2. Veronesi U, Cascinelli N, Mariani L, et al. Twenty-year follow-up of a randomized study comparing breast-conserving surgery with radical mastectomy for early breast cancer. New. Engl. J. Med. 2002;347(16):1227 - 1232.

3. Darby SC, McGale P, Taylor CW, et al. Long-term mortality from heart disease and lung cancer after radiotherapy for early breast cancer: Prospective cohort study of about 300,000 women in US SEER cancer registries. Lancet Oncol. 2005;6(8):557 - 565.

4. Clarke M, Collins R, Darby S, et al. Early Breast Cancer Trialists' Collaborative Group (EBCTCG).Effects of radiotherapy and of differences in the extent of surgery for early breast cancer on local recurrence and 15-year survival: An overview of the randomised trials. Lancet. 2005;366(9503):2087 - 2106.

5. Darby SC, Ewertz M, McGale P, et al. Risk of Ischemic Heart Disease in Women after Radiotherapy for Breast Cancer. New. Engl. J. Med. 2013;368(11):987 - 998.

6. Taylor CW, Povall JM, McGale P, et al. Cardiac dose from tangential breast cancer radiotherapy in the year 2006. Int. J. Radiat. Oncol. Biol. Phys. 2008;72(2):501-507
7. Aznar MC, Korreman S-S, Pedersen AN, et al. Evaluation of dose to cardiac structures during breast irradiation. Br. J. Radiol. 2011;84(1004): 743-746.

8. Carr ZA, Land CE, Kleinerman RA, et al. Coronary heart disease after radiotherapy for peptic ulcer disease. Int. J. Radiat. Oncol. Biol. Phys. 2005;61(3):842-850.

9. Shimizu Y, Kodama K, Nishi N, et al. Radiation exposure and circulatory disease risk: Hiroshima and Nagasaki atomic bomb survivor data, 1950-2003. BMJ. 2010;340:5349.

10. Taylor CW, Povall JM, McGale P, et al. Cardiac Dosefrom tangential breast cancer radiotherapy in the year 2006. Int. J. Radiat. Oncol. Biol. Phys. 2008;72(2):501 - 507.

11. Bartlett FR, Yarnold JR, Donovan EM, Evans PM, Locke I, Kirby AM. Multileaf collimation cardiac shielding in breast radiotherapy: Cardiac doses are reduced, but at what cost? Clin. Oncol. 2013;25(12):690 - 696.

12. Feng M, Moran JM, Koelling T, et al. Development and validation of a heart atlas to study cardiac exposure to radiation following treatment for breast cancer. Int. J. Radiat. Oncol. Biol. Phys. 2011;79(1):10 - 18.

13. Bartelink H, Garavaglia G, Johansson KA, et al. Quality assurance in conservative treatment of early breast cancer. Report on a consensus meeting of the EORTC Radiotherapy and Breast Cancer Cooperative Groups and the EUSOMA (European Society of Mastology). Radiother. Oncol. 1991;22(4):323-326.

14. ICRU. Prescribing, recording and reporting photon beam therapy. ICRU Report 62. 1999.

15. Allen AM, Czerminska M, Jänne PA, et al. Fatal pneumonitis associated with intensity- modulated radiation therapy for mesothelioma. Int. J. Radiat. Oncol. Biol. Phys. 2006;65(3):640 - 645.

16. Stevens CW, Forster KM, Smythe WR, et al. Radiotherapy for mesothelioma. Hematol. Oncol. Clin. North Am. 2005; 19(6):1099 - 1115.

17. Yorke ED, Jackson A, Rosenzweig KE, et al. Correlation of dosimetric factors and radiation pneumonitis for non-small- cell lung cancer patients in a recently completed dose escalation study. Int. J. Radiat. Oncol. Biol. Phys. 2005; 63(3):672 - 682 .

18. Zhang X-J, Sun J-G, Sun J, et al. Prediction of radiation pneumonitis in lung cancer patients: a systematic review. J. Cancer Res. Clin. Oncol. 2012;138(12):2103-2116 
19. Darby SC, McGale P, Taylor CW, et al. Longterm mortality from heart disease and lung cancer after radiotherapy for early breast cancer: prospective cohort study of about 300,000 women in US SEER cancer registries. Lancet Oncol. 2005;6(8):557 - 565.

20. Cheng JCH, Wu JK, Huang CM, et al. Radiationinduced liver disease after radiotherapy for hepatocellular carcinoma: Clinical manifestation and dosimetric description. Radiother. Oncol. 2002; 63(1):41 - 45 .

21. Iavarone M, Colombo M. HBV infection and hepatocellular carcinoma. Clin. Liver Dis. 2013; 17(3):375 - 397

22. McGale P, Darby SC, Hall P, et al. Incidence of heart disease in 35,000 women treated with radiotherapy for breast cancer in Denmark and Sweden. Radiother. Oncol. 2011;100(2):167 - 175.

23. Fowble B, Solin LJ, Schultz DJ, et al. Breast recurrence following conservative surgery and radiation: patterns of failure, prognosis, and pathologic findings from mastectomy specimens with implications for treatment. Int. J. Radiat. Oncol. Biol. Phys. 1990;19(4):833 - 842.

24. Price P, Walsh G, McKinna AJ, et al. Patterns of breast relapse after local excision $+/$ - radiotherapy for early stage breast cancer. Radiother. Oncol. 1988;13(1):53 - 60.

25. Horst KC, Smitt MC, Goffinet DR, et al. Predictors of local recurrence after breast-conservation therapy. Clin. Breast Cancer. 2005;5(6):425 - 438.

26. Jones HA, Antonini N, Hart AA, et al. Impact of pathological characteristics on local relapse after breast-conserving therapy: A subgroup analysis of the EORTC boost versus no boost trial. J. Clin. Oncol. 2009;27(30):4939-47.

27. Kontos M, Allen DS, Agbaje OF, et al. Factors influencing loco-regional relapse in older breast cancer patients treated with tumour resection and tamoxifen. Eur. J. Surg. Oncol. 2011;37(12):1051 $-1058$. 